\title{
Combined Determination of Carbohydrate Antigen 199 and SirT1 Based on an Electrochemiluminescence Immunosensor
}

\author{
Wei Shao ${ }^{1}$ Xiuli Sui ${ }^{2}$ and Guowei Wang ${ }^{3, *}$ \\ ${ }^{1}$ Department of Neurosurgery, Binzhou Medical University Hospital, Binzhou City, Shandong \\ Province, 256603, P.R. China \\ ${ }^{2}$ Clinical laboratory, WenDeng Osteopathy Hospital, WeiHai City, Shandong Province, 250012, P.R. \\ China \\ ${ }^{3}$ Department of Neurosurgery, The First Hospital of Yulin, Yulin City, Shaanxi Province, 719000, \\ P.R. China \\ "E-mail: weishaoneuro@yeah.net
}

doi: $10.20964 / 2017.12 .67$

Received: 18 August 2017 / Accepted: 13 October 2017 / Published: 12 November 2017

\begin{abstract}
In this work, a multi-functionalized graphene oxide (GO) material, where $\mathrm{N}$-(4-aminobutyl)-Nethylisoluminol (ABEI) and either a CA199 antibody or a SirT1 antibody were chemically bound to the surface of magnetic GO (nanoFe $\left.\mathrm{O}_{4} @ \mathrm{GO}\right)$, was fabricated as a one-step electrochemiluminescence (ECL) immunosensor for the ultrasensitive determination of the carbohydrate antigen 199 (CA199) and human sirtuin1 (SirT1). The determination was carried out using a sandwich system, with the quantification of CA199 and SirT1 achieved through potential cycling from +0.6 to $-1.4 \mathrm{~V}$. This strategy was successfully used for the determination of the two tumour markers over the range of 0.3 $\mathrm{fg} / \mathrm{mL}-22 \mathrm{pg} / \mathrm{mL}$, and the limit of detection (LOD) was calculated as $0.15 \mathrm{fg} / \mathrm{mL}$.
\end{abstract}

Keywords: Combined determination; Carbohydrate antigen 199; Electrochemiluminescence method; Glioma diagnosis;

\section{FULL TEXT}

(C) 2017 The Authors. Published by ESG (www.electrochemsci.org). This article is an open access article distributed under the terms and conditions of the Creative Commons Attribution license (http://creativecommons.org/licenses/by/4.0/). 